\title{
A experiência de psicólogos em um programa de residência multiprofissional em saúde ${ }^{1}$
}

\author{
Mharianni Ciarlini de Sousa Bezerra* ${ }^{\text {a* }}$ \\ Vera Engler Cury \\ aUniversidade Federal do Piauí, Campus Ministro Reis Velloso, Parnaíba, Pl, Brasil \\ ${ }^{b}$ Pontifícia Universidade Católica de Campinas, Centro de Ciências da Vida. Campinas, SP, Brasil
}

\begin{abstract}
Resumo: Esta pesquisa objetivou compreender a experiência de psicólogos que vivenciaram a formação em residência multiprofissional em saúde. Consistiu em pesquisa qualitativa de caráter exploratório inspirada na fenomenologia husserliana. Realizaram-se encontros dialógicos, entre a pesquisadora e seis participantes provenientes de programas de residência de um município de São Paulo, analisados por meio de narrativas compreensivas e uma narrativa síntese. Evidenciaram-se quatro elementos experienciais significativos: (1) transformação pessoal e profissional desencadeada pela dedicação integral característica da aprendizagem em serviço; (2) apropriação do ser psicólogo privilegiando a construção de práticas interdisciplinares e integralidade no cuidado; (3) apropriação da atenção psicológica estrategicamente desenvolvida conforme a rede assistencial à saúde; e (4) tensão entre exigências e estratégias de ensino e serviço, que se revelou prejudicial ao processo de aprendizagem. Concluiu-se que as vivências intersubjetivas propiciaram aprendizagens significativas de cunho pessoal e profissional, sinalizando a importância de estratégias pedagógicas que considerem os processos afetivo-emocionais vividos pelos residentes.
\end{abstract}

Palavras-chave: experiência de psicólogos, residência multiprofissional em saúde, fenomenologia, pesquisa qualitativa.

\section{Introdução}

A qualificação de profissionais realizada em contextos de serviços na área de saúde pública prioriza a integração entre a formação e a dinâmica do trabalho e tem sido implementada no Brasil com base na Política Nacional de Formação e Desenvolvimento para o Sistema Único de Saúde (SUS) (Brasil, 2003, 2005a, 2005b). Está pautada no conceito de Educação Permanente em Saúde, visando a aproximação entre as dimensões pedagógica e assistencial na área da saúde, viabilizada pela cooperação técnico-científica entre os ministérios da Saúde e da Educação (Brasil, 2005c, 2009).

$\mathrm{O}$ crescente investimento em programas de residência aponta esta modalidade de formação em serviço como um campo propício a pesquisas desenvolvidas por meio de metodologias interdisciplinares que priorizam as relações de trabalho em equipes multiprofissionais e as práticas profissionais desenvolvidas nesses contextos (Bispo, Tavares, \& Tomaz, 2014; Lopes, 2014; Miranda Neto, Leonello, \& Oliveira, 2015).

* Endereço para correspondência: mh.ciarlini@gmail.com

1 Artigo derivado da dissertação de Mestrado da primeira autora sob orientação da segunda autora, defendida em 2016 no Programa de PósGraduação em Psicologia da Pontifícia Universidade Católica de Campinas. Este trabalho foi realizado com apoio da Coordenação de Aperfeiçoamento de Pessoal de Nível Superior (Capes) - Código de Financiamento 001.
A Residência Multiprofissional em Saúde (RMS) pode ser considerada uma proposta de educação interprofissional que prioriza a aprendizagem em equipe e a flexibilidade da força de trabalho; caracteriza-se como uma modalidade de Pós-Graduação lato sensu que visa potencializar a relação entre teoria e prática no próprio campo de intervenção. Essa formação ocorre em regime de tempo integral e dedicação exclusiva do profissional durante um período mínimo de dois anos, perfazendo uma carga horária semanal de sessenta horas (Brasil, 2007, 2014). Os profissionais que buscam essa modalidade pretendem complementar a Graduação, assegurando uma especialização que atenda ao modelo de integralidade do cuidado e ao trabalho em equipe multiprofissional, preconizados pelo SUS, que raramente são vivenciados nos cursos de Graduação (Ellery, Bosi, \& Loiola, 2013; Silva et al., 2014).

A psicologia esteve presente desde o surgimento dessa modalidade de formação continuada, e vem participando cada vez mais nas diversas áreas de concentração dos programas de RMS (Brasil, 2007, 2012). No entanto, o espaço específico do psicólogo nas equipes de matriciamento técnico-pedagógico ainda não está consolidado no que se refere ao envolvimento e às contribuições da profissão para a saúde pública (Böing, \& Crepaldi, 2010). A perspectiva de articular ações intersetoriais que envolvam serviço, comunidade e universidade, enfatizando uma proposição interdisciplinar, consiste em configuração recente para o psicólogo 
brasileiro. Ao inserir-se em um contexto como este, o psicólogo encontra um ambiente caracterizado por demandas que lhe exigem flexibilidade e capacidade de interação com outros profissionais. Torna-se necessário a todos os profissionais transcender os limites específicos de suas categorias para buscar integrar conhecimentos de outras áreas.

Diante desse cenário, o Conselho Federal de Psicologia (2006) enfatiza que a prática e a formação devem acompanhar a inserção do psicólogo na saúde pública, respeitando as peculiaridades desse campo. Só recentemente foi regulamentada a concessão do título de especialista em Psicologia em Saúde aos egressos de programas de residência profissional e multiprofissional, tendo em vista o crescente número de psicólogos que investem nesse tipo de aprimoramento, diferenciando-se de outras especialidades, como a Hospitalar e a Clínica.

Mesmo com o aumento da participação de psicólogos nesses programas, observa-se ainda uma tímida discussão e produção de pesquisa sobre as práticas psicológicas exercidas nesse contexto. Essa realidade aponta a importância de se investir em estudos que se dediquem à experiência de inserção e aos modos como os psicólogos têm se apropriado de novas práticas a fim de contribuir para a atualização da atenção psicológica na conjuntura institucional de cooperação interprofissional. Nesse sentido, o espaço de formação em saúde que preza pela integralidade dos fazeres profissionais pode ser entendido como valioso campo de estudos pelo seu potencial pedagógico de emergência de novas práticas.

Ao considerar esse panorama, esta pesquisa objetivou compreender a experiência de psicólogos no contexto da formação multiprofissional em saúde, tomando como campo os programas de RMS. Entende-se que, ao se aproximar dos aspectos subjetivos que atravessam a atuação e o modo de apropriação do ser psicólogo nesse contexto, é possível contribuir para uma reflexão sobre a formação em serviço e em equipe a partir dos elementos que os próprios residentes consideram como significativos nesta experiência.

Para tanto, nesta pesquisa o foco de interesse recaiu sobre a experiência subjetiva de psicólogos em fase de conclusão - ou que concluíram recentemente - de um curso de especialização em residência multiprofissional na área da saúde.

\section{Método}

Este estudo configurou-se como uma pesquisa qualitativa de caráter exploratório, ao primar por uma troca intersubjetiva entre participante e pesquisadora, sem propor hipóteses ou conceitos apriorísticos. Descrever e compreender as vivências subjetivas possibilita alcançar os aspectos estruturais de uma experiência tomada como fenômeno a ser investigado (Ales Bello, 2004, 2015). O conceito de experiência utilizado considera a existência de uma relação indissociável entre consciência e objeto, presentificada de modo vivencial pelo sujeito de acordo com uma perspectiva fenomenológica husserliana.

Na concepção de Husserl (1954/2012), o mundoda-vida (mundo vivido ou Lebenswelt) é fundamento tanto à filosofia, como à ciência, enfatizando o sujeito e sua consciência como constituintes do todo existente, de forma a compor um campo de experiências préreflexivas que se revela universal ao compreender a vida enquanto ação dotada de sentido. Considera-se que os elementos da vivência estão interligados na interioridade subjetiva na qual a identificação de um objeto passa pelo reconhecimento das afetações surgidas a partir do contato com ele. Quando um sujeito (pesquisador) se inclina em atitude compreensiva na direção da vivência de outro (participante), implica em uma intencionalidade voltada para a relação intersubjetiva na tentativa de perceber os sentidos que emergem da consciência a partir dessa relação. Desenvolve-se na consciência do sujeito uma unidade de síntese que identifica um objeto, mesmo diante da multiplicidade de modos sob os quais este possa aparecer, ao reconhecer o seu sentido (Husserl, 1931/2013).

Nessa concepção, tudo aquilo de que se tem consciência pode ser tomado como experiência, cuja estrutura comum pode ser acessada pelas pessoas, ainda que seus conteúdos sejam diversos e vivenciados individualmente. A relação do homem consigo e com o mundo passa, necessariamente, pelo conjunto de vivências de diversos tipos que configuram um todo experiencial (Ales Bello, 2015).

Há uma preocupação central nas pesquisas fenomenológicas com os significados experienciais, buscando-se compreender sua complexidade pela descrição do fenômeno como é concretamente vivido. Dessa forma, assume-se uma postura contemplativa que valoriza a realidade do mundo pessoal e relacional (Finlay, 2009). A atitude fenomenológica do pesquisador encerra uma postura marcada por uma abertura à afetação diante do ser humano (Zini, \& Cury, 2014), sendo fundamental a compreensão dos significados que se revelam no contato com as vivências dos participantes por meio do envolvimento ativo do pesquisador.

A análise das vivências permite chegar aos aspectos estruturais dos fenômenos, podendo-se considerar a estabilidade essencial que supera a ideia de relativismo. Adentra-se a experiência pelo seu aspecto estruturante. Então, o processo de elaboração de uma síntese do vivido implica na reunião dos aspectos intencionais que compõem o sentido atribuído às vivências.

\section{Participantes}

Participaram desta pesquisa seis psicólogas provenientes de três programas de residência multiprofissional, desenvolvidos em parceria com a rede municipal de assistência à saúde, desde 2013, por uma universidade do interior do Estado de São Paulo que oferece especializações em regime de residência uniprofissional 
há mais de trinta anos. Dentre as participantes, quatro estavam cursando regularmente o segundo ano da residência e duas haviam concluído o mesmo programa nos últimos seis meses do início da pesquisa. Elas tinham idade média de 25,6 anos e a conclusão do Curso de Graduação em Psicologia havia sido nos últimos cinco anos. Somente duas delas ingressaram na residência sem ter tido outras experiências após a Graduação. Duas delas fizeram curso de aprimoramento profissional de doze meses relacionado à área da saúde em outra instituição de ensino e na modalidade uniprofissional. Outras duas tiveram experiências profissionais em outras áreas antes de cursar a residência. A caracterização das participantes é apresentada na Tabela 1.

Tabela 1. Caracterização das participantes

\begin{tabular}{ccccc}
\hline Nomefictício & Idade & $\begin{array}{c}\text { Programade } \\
\text { Residência }\end{array}$ & $\begin{array}{c}\text { Conclusão da } \\
\text { Graduação }\end{array}$ & $\begin{array}{c}\text { Experiência profissional antes da Residência } \\
\text { Flora }\end{array}$ \\
Rosa & 25 & Saúde da Criança & 2013 & $\begin{array}{c}\text { Psicologia organizacional } \\
\text { (aproximadamente 2 meses) } \\
\text { Aprimoramento em Saúde } \\
\text { da Mulher (12 meses) }\end{array}$ \\
Margarida & 25 & Saúde da Criança & 2012 & $\begin{array}{c}\text { Aprimoramento em Oncologia e } \\
\text { Hematologia Pediátrica (12 meses) }\end{array}$ \\
Dália & 25 & Saúde da Mulher & 2014 & - \\
Violeta & 24 & Urgência e Trauma & 2014 & Psicologia organizacional \\
Verbena & 30 & Saúde da Mulher & 2011 & $\begin{array}{c}\text { (12 meses) e Centro de Referência } \\
\text { em Assistência Social (12 meses) }\end{array}$ \\
\hline
\end{tabular}

\section{Procedimentos}

A pesquisadora, inicialmente, apresentou à coordenação geral do referido programa de residência multiprofissional o projeto da pesquisa a fim de obter autorização para sua realização e averiguar a existência de potenciais participantes da pesquisa.

Após ter obtido autorização para realizar a pesquisa, a pesquisadora submeteu o projeto à Plataforma Brasil para apreciação e aprovação pelo Comitê de Ética em Pesquisa com Seres Humanos. O parecer favorável desse Comitê (código 1.407.524) inaugurou a etapa da pesquisa em que a pesquisadora apresentou a proposta aos coordenadores de cada programa de residência e iniciou contato com as possíveis participantes.

Os objetivos da pesquisa foram devidamente esclarecidos a cada participante por meio da apresentação pela pesquisadora do Termo de Consentimento Livre e Esclarecido (TCLE), ao início de cada encontro; sanadas as eventuais dúvidas, ele foi devidamente assinado. Os encontros individuais com cada uma das seis participantes foram iniciados com a verbalização da seguinte questão norteadora: "Como tem sido, para você, vivenciar a formação profissional em uma equipe multiprofissional em regime de residência?"

Esta questão gerou abertura para dialogar sobre as vivências e os sentidos atribuídos a elas. $\mathrm{O}$ encontro dialógico consistiu no envolvimento existencial entre pesquisadora e participante, configurando um campo fenomenológico experiencial. Ressalta-se que as falas das participantes foram acolhidas pela pesquisadora numa atitude de compreensão empática, da mesma forma em relação aos sentimentos expressos sobre os temas que foram surgindo, espontaneamente, durante cada encontro.

Segundo Stein (1917/2014), a empatia possibilita a apreensão e o conhecimento da vivência do outro. Ao adentrar o mundo das experiências individuais, espera-se que o pesquisador possa compreendê-las a partir das possibilidades de um mundo de experiências generativas disponível a todos. O Eu se mantém estranho ao outro, não ocorrendo uma identificação total, apesar de ser possível a compreensão do que é pensado, vivido e sentido pelo outro. Essa comunicação entre o Outro e o Eu se estende, potencialmente, a todos os sujeitos, caracterizando-se como uma experiência intersubjetiva (Ales Bello, 2014). Assim, a objetivação compreensiva da experiência torna-se possível pela via da vivência empática.

A pesquisadora realizou um encontro dialógico com cada participante ao longo de dois meses, com agendamento de datas, horários e escolha do local em comum acordo com elas. O tempo médio dos encontros foi de 119 minutos de duração - o mais longo durou 155 minutos e o mais breve, 75 minutos.

A análise dos encontros foi realizada a partir da construção de narrativas compreensivas que evidenciaram os significados atribuídos pelas participantes às suas vivências no contexto de formação interprofissional. $\mathrm{O}$ processo de construção das narrativas seguiu a descrição analítica de Stein (1917/2014) sobre a experiência empática. 
A primeira versão da narrativa identificou elementos vivenciados de um modo eminentemente descritivo. Os relatos das participantes emergiram como recordações vívidas, possibilitando rememorar frases literais e descrever situações de modo detalhado. Em seguida, as vivências foram percebidas como revelações afetivas e aspectos nucleares que foram reunidos como núcleos de significados.

A apresentação das narrativas a outros pesquisadores, no contexto do Grupo de Pesquisa institucional, possibilitou a elucidação de elementos significativos das vivências das participantes. Nessa etapa, a pesquisadora elaborou nova organização dos elementos textuais da narrativa, tendo assumido, de modo mais efetivo, o seu lugar na investigação sistemática do fenômeno e se ocupando da compreensibilidade comunicativa do que lhe foi evidenciado nesse percurso.

Ao final desse processo, uma narrativa síntese, contendo os elementos interpretativos acerca do conjunto das seis narrativas, possibilitou compor a estrutura essencial do fenômeno. A etapa de conclusão do processo investigativo foi efetivada pela discussão de cada elemento essencial à luz de outras pesquisas ou teorizações da comunidade científica que auxiliaram no processo de interpretação do fenômeno em suas múltiplas dimensões sociais.

\section{Resultados}

A escuta ativa dos conteúdos vivenciais possibilitou que as singularidades do fenômeno vivido pelas participantes fossem esclarecidas à medida que se revelavam no diálogo com a pesquisadora. Cada participante, a seu modo, narrou o próprio percurso de formação profissional na Psicologia, retomando desde o princípio o processo de escolha pela especialização na área da saúde. Constatou-se que a dedicação integral à formação em serviço, permitindo que os residentes atuem nos três níveis de atenção em que está organizado o SUS, consiste em aspecto central em que se estruturam as vivências nos programas de residência em saúde.

As participantes vivenciaram mudanças significativas nos aspectos regimentais das residências, que desencadearam no modelo pedagógico dos programas frequentados, compartilhando cenários de práticas e de ensino, a depender dos estágios programados para atender às exigências de suas áreas de concentração. As especificidades de cada programa conduziramnas a implementarem seus processos de trabalho nas Unidades Básicas de Saúde (UBS), no Serviço de Atenção Domiciliar (SAD), no Serviço de Atendimento Móvel de Urgência (Samu), além dos diversos setores do hospital, incluindo pronto-atendimento, ambulatórios especializados, enfermarias, centros cirúrgicos e unidades de terapia intensiva.
Durante essa formação, as psicólogas participantes estabeleceram novas relações profissionais, descobriram as particularidades do campo de atuação e as fronteiras entre as áreas envolvidas. A experiência como residente revelou tanto um modo de sofrimento ante as dificuldades vivenciadas cotidianamente, compartilhado com os colegas, como também sentimentos de realização pessoal, em decorrência da percepção de terem transposto obstáculos e se apropriado dos próprios limites e potencialidades.

A seguir, são descritos os quatro elementos estruturais que compuseram as vivências das psicólogas participantes em relação ao fenômeno em foco nesse estudo. Eles se revelaram interligados pelo conjunto de significados atribuídos por elas ao processo, ao mesmo tempo, singular e coletivo.

(1) O processo de transformação pessoal e profissional é propiciado pelo contato com circunstâncias desafiadoras que contribuem para uma aprendizagem significativa sobre suas competências profissionais e para a mudança de percepção sobre si mesmas e sobre a profissão. Elas puderam avaliar as próprias competências e os valores profissionais, aprendendo a caminhar com autonomia e assumindo responsabilidade pela execução do trabalho e dos procedimentos institucionais concernentes ao mesmo.

(2) A apropriação do ser psicólogo privilegiando a construção de práticas coletivas interdisciplinares e a integralidade no cuidado pela equipe multiprofissional revelaram-se dimensões significativas da experiência, pois as participantes puderam planejar e executar ações de cuidado com profissionais de outras especialidades, convivendo com e em equipes de trabalho. Elas desenvolveram suas práticas articulando-se, constantemente, com outros profissionais dos serviços de saúde por considerarem que a atenção psicológica necessita estar embasada numa concepção de cuidado integral ao paciente que tangencia outras especialidades.

(3) A apropriação da atenção psicológica estrategicamente desenvolvida em conformidade com a rede assistencial à saúde evidenciou uma aprendizagem experiencial em torno do ser psicólogo nesse contexto, articulada com o compromisso ético com os pacientes e a equipe de trabalho, diante da necessidade de implementar intervenções de acordo com o preconizado em cada nível de atenção à saúde.

(4) A tensão entre as estratégias de ensino e de serviço revelou-se através da tentativa de equilibrar interesses relativos ao aprimoramento técnico e à atuação nos serviços de saúde. A realidade dos serviços sobrepõe-se às ações pedagógicas, exigindo dos residentes maior empenho para atender o grande volume de demandas. Resultante da iniciativa das equipes, as discussões interprofissionais são mais valorizadas pelos residentes e consideradas estratégias potencializadoras de aprendizagem teórico-prática. 


\section{Discussão}

Consoante aos resultados encontrados nessa pesquisa, outros pesquisadores afirmam que as situações de sofrimento sobressaem em relação às vivências de gratificação na experiência de formação de residentes. Evidenciam-se alguns elementos que contribuem para que os residentes vivenciem sofrimento: a responsabilidade pelo processo de aquisição de novos conhecimentos, o número excessivo de atividades assumidas no serviço, o pouco reconhecimento da equipe e a dificuldade para realizar atividades concernentes a outros profissionais. Em contrapartida, a valorização do trabalho por meio das atividades multiprofissionais desenvolvidas pode desencadear vivências de prazer e satisfação (Fernandes, et al. 2015).

Considerando-se o que foi destacado em relação às vivências de ensino em serviço, constata-se que a residência, como modalidade de formação, é propiciadora de mudanças pessoais e profissionais em função de uma aprendizagem significativa (Rogers, 1969/1977). O envolvimento colaborativo de tutores e preceptores é evidenciado como facilitador dessa dinâmica de descobertas. Além disso, a própria equipe de residentes constitui-se em um grupo de facilitação para a aprendizagem e $o$ amadurecimento profissional de um ponto de vista individual, uma vez que a identificação com o grupo advém das vivências compartilhadas, possibilitando encarar limites e superar entraves pessoais.

Pode-se afirmar que a aprendizagem propiciada pelo ensino em serviço estimula a criação de estratégias individuais de cunho experiencial, evidenciando um processo dinâmico de adaptação às distintas realidades encontradas nos dispositivos assistenciais de saúde. Admitir a necessidade de cuidado consigo, com o outro e com a profissão desenha o pano de fundo dessa experiência. As mudanças ressaltadas pelas participantes reúnem aspectos particulares que conduzem a um compromisso diferenciado consigo e com a profissão, socialmente mais implicado com métodos que visam à saúde integral.

Nesse sentido, entende-se que as forças integrativas do self reorganizam-se nesse processo a partir do campo perceptivo, gerando mudanças comportamentais, conforme enfatiza Rogers (2010). Assim, a experiência vivida na condição de residentes foi significada pelas participantes em seus processos de atualização subjetiva, tornando-as potencialmente mais capazes de adaptação psicossocial, permitindo que elaborassem vivências de modo integrado e respeitando a alteridade na relação com o mundo.

As participantes depararam-se continuamente com a necessidade de estabelecerem uma relação interprofissional satisfatória, para que pudessem cumprir suas obrigações. Passos (2013) esclarece que a origem da prática multidisciplinar remete à transição da medicina de especialidades para a medicina integral, numa tentativa de superação do saber fragmentado e da interferência parcial ao sujeito adoecido. As ações terapêuticas e preventivas, exercidas de modo integrado pelas diversas especialidades que compõem a equipe de saúde, privilegiam uma visão global do paciente. Dessa forma, as modulações desse saber-fazer experiencial apontam para uma perspectiva atual de cuidado transversal aos múltiplos saberes.

Pesquisas recentes assinalam que o aumento de categorias profissionais atuando conjuntamente promove o fortalecimento das ações de saúde e a resolutividade no enfrentamento de problemas (Domingos, Nunes, \& Carvalho, 2015; Motta, \& Pacheco, 2014). Nessa perspectiva, a educação interprofissional destaca-se como iniciativa mundial, ao transformar o trabalho multiprofissional na área da saúde, primando pela integralidade aliada à interdisciplinaridade ao efetivar a atenção centrada no paciente (Reeves, 2016; Reeves et al., 2008; World Health Organization, 2010).

Entende-se que a aprendizagem que se dá de maneira coletiva na residência proporciona aos profissionais um treinamento sistemático em direção a uma prática interdisciplinar. No entanto, a maneira como cada profissional significa esse processo difere conforme sua percepção sobre o cuidar e seu compromisso com essa proposta. Nesta pesquisa, a experiência em equipe foi vivenciada de maneira ambígua pelas participantes: ora sentiram-se parte essencial de um coletivo coeso, ora perceberam-se isoladas.

Amatuzzi (2010) esclarece que grupos e pessoas podem potencializar-se mutuamente, embora não signifique que compartilham, necessariamente, os mesmos processos. Nesse sentido, as participantes perceberam que a profissão exercida em parceria com outras áreas potencializa seu poder de ação e eficácia, revelando suas particularidades a partir do que vivenciam coletivamente. As vivências nos diferentes campos de prática contribuíram para que desenvolvessem habilidades e estratégias técnicas em prol da melhor qualidade e resolutividade de suas ações, a fim de promover uma atenção centrada no paciente.

As vivências assinaladas pelas participantes apontam para uma identificação com algumas subáreas da saúde, sobressaindo-se a Psicologia Hospitalar como ênfase predominante, confirmando sua peculiar tradição no contexto brasileiro. Kind (2010) argumenta que as discussões em torno das ambiguidades existentes entre as especialidades hospitalar e clínica, de acordo como estão definidas pelo Conselho Federal de Psicologia, contribuem para manter o debate em torno das especificidades de cada uma, além de legitimar uma prática hospitalar em conformidade com o modelo de especialidades médicas.

Alguns estudos esclarecem que o trabalho do psicólogo hospitalar é definido pelo contexto no qual ele atua, diferenciando-se da perspectiva mais abrangente da Psicologia da Saúde (Azevêdo, \& Crepaldi, 2016). Passos, Hilbert e Duarte (2014) afirmam que a prática psicológica no contexto da saúde pública deve extrapolar o modelo 
clássico de atenção clínica, delimitado por contextos específicos e intervenções isoladas. Nessa perspectiva, a continuidade da assistência dependerá do que for revelado nesse processo, incluindo as discussões interdisciplinares baseadas em métodos interativos.

As participantes mencionaram as seguintes práticas como destaques da atenção psicológica exercida por elas no hospital: o acolhimento; a escuta ativa e a intervenção de urgência; além de exercerem a função de mediadoras da comunicação entre pacientes e equipes da assistência hospitalar. Entre as principais demandas citadas, enfatizaram: a comunicação de más notícias relativas à condição do paciente; as implicações relativas ao processo de assumir novas responsabilidades ao se tornar pai ou mãe; e o sofrimento emocional decorrente de situações-limite (acidentes, traumas e mortes) ou devido ao próprio tratamento (cirurgias e terapias invasivas). Ao mesmo tempo, elas ressaltaram a importância de se considerar os aspectos sociais do paciente e de sua família no exercício da atenção psicológica na saúde pública, especialmente por terem sido impactadas pela realidade marcada pela vulnerabilidade com a qual se depararam nos diversos locais de atuação.

Ferreira Neto (2010) afirma que a inserção dos psicólogos nas políticas públicas de saúde os confronta com segmentos da população diferenciados da clientela de classe média, associada à prática clínica tradicional. Esse encontro evidencia a importância de se promoverem rearranjos no modo de atuação e na formação do psicólogo, conforme destacaram as participantes desta pesquisa.

A visão tradicional do hospital compartilhada pelas participantes, em comparação com os serviços extra hospitalares, revela uma concepção de rede assistencial fragmentada. A continuidade do cuidado interprofissional foi mencionada pelas participantes como vivência específica do contexto hospitalar. Para Mendes (2011), a fragmentação entre os pontos de atenção à saúde e a difícil comunicação entre as equipes caracteriza um sistema de saúde pouco integrado enquanto rede assistencial.

Pesquisas recentes apontam para as potencialidades e desafios que fazem dos modelos de educação interprofissional importantes caminhos de articulação entre as profissões para fins de integralidade do cuidado nos serviços de saúde (Peduzzi, Norman, Germani, Silva, \& Souza, 2013; Reeves et al., 2008). No caso desta pesquisa, observou-se que os projetos curriculares dos programas propõem espaços que privilegiam a relação dialógica intraequipes de residentes e a troca de saberes por meio de módulos de aprendizagem integrados, mas o envolvimento das equipes assistenciais nesse propósito fica a cargo do serviço e ocorre de modo individualizado.

Em estudo sobre os programas de residência e a integralidade da atenção, Shikasho (2013) analisa a micropolítica do trabalho e da formação em saúde e enfatiza que um importante efeito desse modelo consiste no estímulo ao protagonismo dos profissionais. Essa realidade pode estar relacionada à tentativa de implementar estratégias pedagógicas que primem pela configuração de cenários de aprendizagem que considerem os sujeitos envolvidos como protagonistas sociais, responsáveis pelo próprio processo de formação.

No tocante aos desafios da educação interprofissional apontados pelos pesquisadores, ressaltam-se: uma cultura universitária caracterizada pela fragmentação dos saberes; o difícil estabelecimento de relações horizontais entre os profissionais de saúde; os obstáculos à construção coletiva de projeto pedagógico; e o investimento necessário ao desenvolvimento de docentes (Batista, Rossit, \& Batista, 2013).

A residência multiprofissional em saúde, proposta em acordo com o modelo de Rede Assistencial à Saúde, deveria promover uma maior integração entre os pontos de atenção, atendendo às exigências características de cada nível de complexidade. As ações de cuidado em cada setor devem superar o modo compartimentalizado com que ainda se organizam, assumindo funções mais integradas nesta proposta de ensino em serviço. No entanto, a falta de mão de obra qualificada nos diversos pontos da rede de atenção implica numa difícil problemática enfrentada pelos programas de residência, especialmente pela maneira como os residentes são levados pelos gestores a suprir esta carência num claro desvirtuamento de sua formação.

\section{Considerações finais}

A compreensão acerca de uma dimensão pouco conhecida, como a vivência subjetiva dos residentes, tornou-se possível a partir dos pressupostos fenomenológicos que embasaram esta pesquisa. A escuta ativa dos conteúdos vivenciais proporcionou que as singularidades do fenômeno vivido pelas participantes fossem esclarecidas à medida que se revelavam no diálogo com a pesquisadora. Assim, os encontros dialógicos evidenciaram a potencialidade da compreensão empática, trazendo à tona o cerne da experiência pessoal originária que supõe aspectos estruturais da experiência humana. Nesse percurso metodológico, a elaboração e o refinamento das narrativas adquiriram uma conotação artesanal no processo de compreensão e interpretação dos elementos.

$\mathrm{O}$ ato reflexivo que visa a suspensão de conteúdos prévios aos encontros dialógicos, para se chegar à essência do fenômeno em foco, evidenciou-se como relevante contribuição da Fenomenologia ao campo das pesquisas envolvendo a formação profissional na saúde. Tendo em vista o necessário distanciamento das questões que atravessam interesses pessoais ou políticos que atribuem vieses anticientíficos aos estudos.

Nesta pesquisa, emergiram elementos que fazem do processo de mudanças profissionais uma jornada transformadora que se revela como um processo subjetivo. A análise desses elementos gerou reflexões em torno dos significados atribuídos pelas participantes à formação 
multiprofissional em residência, esclarecendo acerca da importância de se pensar espaços que promovam o acolhimento aos profissionais residentes ao longo do curso. Nesse sentido, atenta-se para as transformações pessoais e profissionais vividas pelas participantes marcadas pelo sofrimento concomitante às circunstâncias propiciadoras de aprendizagem significativa.

Destaca-se a necessidade de elaboração de estratégias metodológicas de ensino que considerem a participação ativa dos atores envolvidos, de maneira a contribuírem com o aprimoramento dos cursos. Os significados atribuídos ao ser psicólogo na área da saúde atuando em equipe multiprofissional de modo colaborativo relacionam-se às práticas de atenção psicológica que prezam pela integralidade do cuidado na rede assistencial. Contudo, a identificação com a Psicologia Hospitalar pode ser percebida como um resquício da visão fragmentada que tende a privilegiar o modelo médico predominante nesse contexto.

As vivências de conflito entre as dimensões do ensino e de serviço trouxeram à mostra uma problemática presente nos debates sobre a regulamentação de residências propostas por instituições dedicadas exclusivamente ao serviço. Neste sentido, destaca-se a importância da participação das instituições universitárias como propiciadoras de recursos ambientais e humanos necessários ao exercício crítico e reflexivo da formação. No entanto, no que concerne aos contextos em que se realizam as práticas de saúde, ainda apresentam entraves estruturais e dificuldades operacionais para a efetivação dos cuidados preconizados pelas diretrizes da política de saúde pública vigente no país. Esse tensionamento resvala na própria concepção que o profissional residente mantém sobre o seu fazer, dificultando o reconhecimento da sua função em cada etapa e local de atuação.

Outro ponto que merece destaque consiste na atenção dada ao sentido individual que se revelou nos relatos das participantes, quando acolhidas como pessoas que atravessam um processo humano significativo. Logo, cabe ressaltar o sentido experiencial dessa formação, que sobressai em relação à dimensão política tão explorada nas pesquisas sobre educação em saúde e sinaliza a importância de novas pesquisas que abordem a subjetividade de outras categorias de profissionais em formação. Portanto, sugere-se que os cursos de residência criem estratégias grupais para acolher de maneira empática a experiência de aprendizagem dos residentes, a fim de potencializar a autonomia e a criatividade despertadas nas relações intersubjetivas que são vivenciadas cotidianamente na formação em serviço.

\section{The experience of psychologists in a health multiprofessional internship program.}

Abstract: This study analyzed the experience of psychologists who went through a multiprofessional internship in public health. It is a qualitative and exploratory investigation inspired by Husserl's phenomenology. The researcher held dialogical encounters with six participants who attended different Multiprofessional Internship Programs in a town in the state of São Paulo, which were then analyzed by composition of comprehensive narratives and a synthesis narrative. Four significant experiencial elements were observed: (1) personal and professional growth stemming from learning in full dedication to the internship; (2) a reassessment of the psychologists' role regarding integrated and interdisciplinary healthcare; (3) a reassessment of psychological attention following an integrated health system; (4) tension between academic and health service demands and strategies interfered negatively on the learning process. Conclusion: the intersubjective experiences provided significant personal and professional learning, implying the importance of pedagogical strategies that consider the affective-emotional processes experienced by residents.

Keywords: lived experience of psychologists, health multiprofessional internship, phenomenology, qualitative research.

\section{L'expérience des psychologues dans un programme de résidence médicale multidisciplinaire}

Résumé: Cette recherche visait à comprendre l'expérience de psychologues ayant fait l'expérience de formation en résidence dans des établissements de santé multidisciplinaires. II s'agissait de recherches exploratoires qualitatives basées sur la phénoménologie husserlienne. Des réunions de dialogue ont eu lieu entre la chercheuse et six participants de programmes de résidence dans une ville de São Paulo, analysées par des récits détaillés et un récit de synthèse. Quatre éléments expérientiels significatifs sont évidents: (1) la transformation personnelle et professionnelle déclenchée par le dévouement total caractéristique de l'apprentissage en cours; (2) l'appropriation du psychologue privilégiant la construction de pratiques interdisciplinaires et l'intégralité des soins; (3) l'appropriation des soins psychologiques stratégiquement développés en fonction du réseau de santé; (4) la tension entre les exigences d'enseignement et de service et les stratégies préjudiciables au processus d'apprentissage. Conclusion : les expériences intersubjectives ont fourni un apprentissage personnelle et professionnelle significatif, signalant l'importance des stratégies pédagogiques qui tiennent compte des processus affectifs-émotionnels vécus.

Mots-clés: expérience de psychologues, résidence de santé multidisciplinaire, phénoménologie, recherche qualitative. 


\section{La experiencia de psicólogos en un programa de residencia multiprofesional en la salud}

Resumen: Esta investigación objetivó comprender la experiencia de psicólogos que han experimentado la formación en residencia multiprofesional en la salud. Es una investigación cualitativa, de carácter exploratorio, basándose en la fenomenología husserliana. Hubo reuniones dialógicas entre la investigadora y seis participantes de programas de residencia en un municipio de São Paulo, que fueron analizadas utilizando narrativas comprensivas y una síntesis narrativa. Se presentaron cuatro elementos experienciales significativos: (1) transformación personal y profesional provocada por el servicio de aprendizaje que requiere dedicación completa; (2) apropiación de la forma de ser un psicólogo que se centra en la construcción de prácticas interdisciplinarias e integridad en el cuidado; (3) apropiación de estrategias de atención psicológica desarrolladas según la red de atención a la salud; y (4) tensión entre exigencias y estrategias de enseñanza y servicio, que resultó perjudicial para el proceso de aprendizaje. Se concluye que las experiencias intersubjetivas proporcionaron aprendizajes personal y profesional significativos, lo que apunta a la importancia de estrategias pedagógicas que consideren los procesos afectivo-emocionales experimentados por los residentes.

Palabras clave: experiencias de psicólogos, residencia multiprofesional en la salud, fenomenología, investigación cualitativa.

\section{Referências}

Ales Bello, A. (2004). Fenomenologia e ciências humanas: psicologia, história e religião. Bauru, SP: Edusc.

Ales Bello, A. (2014). Edith Stein: a paixão pela verdade. Curitiba, SC: Juruá.

Ales Bello, A. (2015). Pessoa e Comunidade: comentários: psicologia e ciências do espirito de Edith Stein. Belo Horizonte, MG: Artesã.

Amatuzzi, M. M. (2010). Por uma psicologia humana. Campinas, SP: Alínea.

Azevêdo, A. V. S., \& Crepaldi, M. A. (2016). A Psicologia no hospital geral: aspectos históricos, conceituais e práticos. Estudos de Psicologia, 33(4), 573-585. doi: 10.1590/1982-02752016000400002

Batista, S. H., Rossit, R., \& Batista, N. A. (2013). Educação interprofissional, interdisciplinaridade e a formação em saúde: potências e desafios. In G. T. R. Silva (Org.). Residência multiprofissional em saúde: vivências e cenários da formação (pp. 29-46). São Paulo, SP: Martinari.

Bispo, E. P. F., Tavares, C. H. F., \& Tomaz, J. M. T. (2014). Interdisciplinaridade no ensino em saúde: o olhar do preceptor na Saúde da Família. Interface: Comunicação, Saúde, Educação, 18(49), 337-350. doi: 10.1590/1807-57622013.0158

Böing, E., \& Crepaldi, M. (2010). O psicólogo na atenção básica: uma incursão pelas políticas públicas de saúde brasileiras. Psicologia: Ciência e Profissão, 30(3), 634-649. doi: 10.1590/S1414-98932010000300014

Brasil. (2003). Resolução $\mathrm{n}^{\circ} 335$, de 27 de novembro de 2003. Afirma a aprovação da "Política Nacional de Formação e Desenvolvimento para o SUS: Caminhos para a Educação Permanente em Saúde" e a estratégia de "Pólos ou Rodas de Educação Permanente em Saúde" como instâncias locorregionais e interinstitucionais de gestão da Educação Permanente. Brasília, DF: Ministério da Saúde. Recuperado de https://bit.ly/31ztBaH
Brasil. (2005a). Princípios e Diretrizes para a gestão de trabalho no SUS (NOB/RH-SUS) (3a. ed.). Brasília, DF: Ministério da Saúde.

Brasil. (2005b). Lei n ${ }^{\circ} 11.129$, de 30 de junho de 2005. Institui o Programa Nacional de Inclusão de Jovens - ProJovem; cria o Conselho Nacional da Juventude - CNJ e a Secretaria Nacional de Juventude; altera as Leis $\mathrm{n}^{\circ} 10.683$, de 28 de maio de 2003, e 10.429, de 24 de abril de 2002; e dá outras providências. Diário Oficial da União, seção 1.

Brasil. (2005c). Portaria Interministerial $n^{0} 2.117$, de 3 de novembro de 2005. Institui no âmbito dos Ministérios da Saúde e da Educação, a Residência Multiprofissional em Saúde e dá outras providências. Diário Oficial da União, seção 1 .

Brasil. (2007). Resolução ${ }^{\circ} 1$ de 8 de junho de 2007. Estabelece normas de curso de especialização latu senso, em nível de especialização. Diário Oficial da União, seção 1.

Brasil. (2009). Política Nacional de Educação Permanente em Saúde. Brasília, DF: Ministério da Saúde. Recuperado de https://bit.ly/3gAz99d

Brasil. (2012). Resolução n ${ }^{\circ}$ 2, de 13 de abril de 2012. Dispõe sobre Diretrizes Gerais para os Programas de Residência Multiprofissional e em Profissional de Saúde. Diário Oficial da União, seção 1.

Brasil. (2014) Resolução n 7, de 13 de novembro de 2014. Regulamenta os processos de avaliação, supervisão e regulação de programas de residência em área profissional da saúde. Diário Oficial da União, seção 1.

Conselho Federal de Psicologia. (2006). Relatório final do I Fórum Nacional de Psicologia e Saúde Pública: contribuições técnicas e políticas para avançar o SUS. Brasília, DF: Conselho Federal de Psicologia. Recuperado de https://bit.ly/32NhKFc

Domingos, C. M., Nunes, E. F. P. A., \& Carvalho, B. G. (2015). Potential of multiprofessional residency on family healthcare: the view of healthcare workers. 
Interface: Comunicação, Saúde, Educação, 19(55), 1221-1232. doi: 10.1590/1807-57622014.0653

Ellery, A. E. L., Bosi, M. L. M., \& Loiola, F. A. (2013). Integração ensino, pesquisa e serviços em saúde: antecedentes, estratégias e iniciativas. Saúde e Sociedade, 22(1), 187-196. doi: 10.1590/S0104-12902013000100017

Fernandes, M. N. S., Beck, C. L. C., Weller, T. H., Viero, V., Freitas, P.H., \& Prestes, F. C. (2015). Sofrimento e prazer no processo de formação de residentes multiprofissionais em saúde. Revista Gaúcha de Enfermagem, 36(4), 90-97. doi: 10.1590/1983-1447.2015.04.50300

Ferreira Neto, J. L. (2010). A atuação do psicólogo no SUS: Análise de alguns impasses. Psicologia, Ciência e Profissão, 30(2), 390-403. doi: 10.1590/S1414-98932010000200013

Finlay, L. (2009). Debating phenomenological research methods. Phenomenology \& Practice, 3(1), 6-25. Recuperado de: https://bit.ly/2ECPAob

Husserl, E. (2012). A crise das ciências europeias e a fenomenologia transcendental: uma introdução à filosofia fenomenológica. (D. F. Ferrer, trad.). Rio de Janeiro, RJ: Forense. (Trabalho original publicado em 1954)

Husserl, E. (2013). Meditações cartesianas e conferências de Paris: de acordo com o texto de Husserliana I. (P. M. S. Alves, trad.). Rio de Janeiro, RJ: Forense. (Trabalho original publicado em 1931)

Kind, L. (2010). Psicologia e Saúde: a produção de estilos de pensamento. Latin American Journal of Fundamental Psychopathology Online, 7(1), 113-129. Recuperado de: https://bit.ly/3gAtP1Z

Lopes, E. F. S. (2014). A formação em serviço no Programa de Residencia Integrada Multiprofissional em Saúde do Hospital de Clínicas de Porto Alegre (PRIMS/HCPA) (Tese de doutorado). Universidade Federal do Rio Grande do Sul, Porto Alegre. Recuperado de: https://bit.ly/3ji8Tly

Mendes, E. V. (2011). As redes de atenção à saúde. Brasília, DF: Organização Pan-Americana da Saúde.

Miranda Neto, M. V., Leonello, V. M., \& Oliveira, M. A. C. (2015). Multiprofessional residency in health: a document analysis of political pedagogical projects. Revista Brasileira de Enfermagem, 68(4), 586-593. doi: 10.1590/0034-7167.2015680403i

Motta, L. B., \& Pacheco, L. C. (2014). Integrating medical and health multiprofessional residency programs: the experience in building an interprofessional curriculum for health professionals in Brazil. Education for Health, 27(1); 83-88. doi: 10.4103/1357-6283.134331

Passos, E. (2013). A construção da clínica comum e as áreas profissionais. In A. A. Capozzolo, S. J. Casetto, \& A. O. Henz (Org.), Clínica comum: itinerários de uma formação em saúde (pp. 213-228). São Paulo, SP: Hucitec.
Passos, I. C. R., Hilbert, S. N., \& Duarte, T. A. E. (2014). Clínica ampliada: a atuação em rede e promoção de saúde. In N. A. G. Nucci, \& N. J. Faria (Org.), Psicologia e saúde: reflexões humanistas (pp. 95-106). Campinas, SP: Alínea.

Peduzzi, M., Norman, I. J., Germani, A. C. C. G., Silva, J. A. M., \& Souza, G. C. (2013). Interprofessional education: training for healthcare professionals for teamwork focusing on users. Revista da Escola de Enfermagem da USP, 47(4), 973-979. doi: 10.1590/S0080-623420130000400029

Reeves, S. (2016). Why we need interprofessional education to improve the delivery of safe and effective care. Interface: Comunicação, Saúde, Educação, 20(56), 185197. doi: 10.1590/1807-57622014.0092

Reeves, S., Zwarenstein, M., Goldman, J., Barr, H., Freeth, D., Hammick, M, et al. (2008). Interprofessional education: effects on professional practice and health care outcomes (Review). Cochrane Database of Systematic, 1(CD002213). doi: 10.1002/14651858.CD002213.pub2.

Rogers, C. R. (1977). Liberdade para aprender. (4a. ed., E. G. M. Machado, \& M. P. Andrade, trad.). Belo Horizonte, MG: Interlivros. (Trabalho original publicado em 1969).

Rogers, C. R. (2010). Algumas observações sobre a organização da personalidade. In J. R. Doxsey, L. M. Assumpção, M. A. Tassinari, M. Japur, M. A. Serra, R. Wrona, et al. (Org.). Abordagem centrada na pessoa (pp. 45-70). Vitória, ES: Edufes.

Shikasho, L. (2013). Os Programas de Residência e a Integralidade da Atenção: um estudo sobre a micropolítica do trabalho e da formação em saúde (Dissertação de mestrado). Universidade Federal de Juiz de Fora, Juiz de Fora. Recuperado de https://bit.ly/3jeRryi

Silva, C. T., Terra, M. G., Camponogara, S., Kruse, M. H. L., Roso, C. C., \& Xavier, M. S. (2014). Educação permanente em saúde a partir de profissionais de uma residência multidisciplinar: estudo de caso. Revista Gaúcha de Enfermagem, 35(3), 49-54. doi: 10.1590/1983- 1447.2014.03.44512

Stein, E. (2014). Il problema dell'empatia. Roma: Edizioni Studium. (Trabalho original publicado em 1917).

World Health Organization. (2010). Framework for action on interprofessional education \& collaborative practice. Genebra: World Health Organization.

Zini, R., \& Cury, V. E. (2014). Acolhimento como prática psicológica no contexto de um Centro de Atenção Psicossocial em álcool e drogas. Memorandum, 27, 39-60. Recuperado de: https://bit.ly/3hDCTry

Recebido: 14/06/2019

Revisado: 28/01/2020

Aprovado: 08/08/2020 